\title{
PENGEMBANGAN MODEL PEMELAJARAN CERITA RAKYAT MELALUI COPYWRITING
}

\author{
Vinna Apriola
}

\begin{abstract}
Development model this folklore lesson is background by writer desire which have profession as teacher to bear special lesson model this subject and of a kind, bearing better lesson condition in student easiness and class to fond of to read folklore. This research And development aim to give information about existence one of effective lesson model in course of folklore lesson to Indonesian teacher, and as positive input in development model folklore lesson for the sake of furthermore. This Research type is research qualitative using method R\&D (Research And Development). Research checking and developing folklore lesson model in class.This Research instrument is interview do not the structure, and respon assessment enquette addressed to coleage and student as valid determinant of product, and also the field note hit things that happened in product test in class. This Research data is product in the form of substance teach to print containing of development execution guide model folklore lesson of through copywriting which tried with instrument. Result obtained from research product test applied in class XI IPS 3 SMA Plus Negeri 7 Kota Bengkulu in teaching year 2012 on Wednesday, 16 May 2012 beating 08.45-10.15 WIB is effective, according to, and draw.
\end{abstract}

key words: the development model learning, folklore, copywriting

\section{Pendahuluan}

Pendidikan merupakan suatu kegiatan yang dijiwai dan dilandaskan pada nilainilai dan tujuan. Pendidikan yang kegiatannya dijiwai oleh Pancasila dan UUD 1945 yang tertuang dalam UU no. 20 tahun 2003 tentang sistem pendidikan nasional, BAB 1 Pasal 1 ayat 2 yang berbunyi, "Pendidikan Nasional adalah pendidikan yang berdasarkan Pancasila dan UUD 1945 yang berakar pada nilai-nilai keagamaan, kebudayaan nasional, dan tanggap terhadap perubahan zaman". Pendidikan tersebut mengarah pada tujuan pendidikan nasional yang terkandung dalam juga dalam UU no. 20 tahun 2003 tentang sistem pendidikan nasional BAB II Pasal 3, yaitu:"Pendidikan nasional berfungsi mengembangkan kemampuan dan membentuk watak serta peradaban bangsa yang bermartabat dalam rangka mencerdaskan kehidupan bangsa, bertujuan untuk mengembangkan potensi peserta didik agar menjadi manusia yang beriman dan bertakwa kepada Tuhan Yang Maha Esa, berakhlak mulia, sehat, berilmu,cakap, kreatif, mandiri, dan menjadi warga negara yang demokratis serta bertanggung jawab". pesertadidik dengancerita rakyat dibawah bimbingan guru dan pengembangan model pemelajaran yang efektif, asyik, dan menyenangkan serta memiliki apresiasi yang memadai akan menjadi atau memberikan pengalaman yang indah bagi peserta didik. Sehubungan dengan hal tersebut, maka penulis mengajukan penelitian ini. Di samping itu, peneliti ingin menumbuhkan kegemaran membaca cerita rakyat pada siswa. Permasalahan 
yang dibahas dalam penelitian ini, yaitu: apakah penerapan pengembangan model pemelajaran cerita rakyat melalui copywriting yang dilakukan di kelas XI IPS 3 SMA Plus Negeri 7 Kota Bengkulu efektif?. Dengan tujuan penulisan dalam penelitian ini utamanya adalah untuk mengetahui keefektifan penerapan pengembangan model pemelajaran cerita rakyat melalui copywriting di kelas XI IPS 3 SMA Plus Negeri 7 Kota Bengkulu.

Temuan penelitian ini diharapkan, (1) memberikan informasi tentang model pemelajaran yang efektif dalam proses pemelajaran cerita rakyat kepada guru bahasa Indonesia, dan (2) sebagai masukan positif dalam pengembangan model pemelajaran cerita rakyat untuk kepentingan lebih lanjut. Sementara itu, produk yang diharapkan dari penelitian ini adalah buku yang berisi pedoman pengembangan model pemelajaran cerita rakyat melalui copywriting yang diperuntukkan untuk guru.

Metode penelitian yang digunakan adalah penelitian kualitatif dengan model R\&D (Research and Development) dengan subjek kelas XI IPS 3 SMA Plus Negeri 7 Kota Bengkulu. Instrumen penelitian ini adalah wawancara tak terstruktur, dan angket penilaian serta respon yang ditujukan ke siswa dan teman sejawat sebagai penentu kevalidan produk. Di samping itu digunakan juga catatan lapangan mengenai hal-hal yang terjadi dalam uji produk di kelas. Data penelitian ini adalah produk dalam bentuk bahan ajar cetak yang berisi petunjuk pelaksanaan pengembangan model pemelajaran cerita rakyat melalui copywriting yang diujicobakan dengan instrumen.

\section{Langkah-Langkah dan Metode} Penelitian

Research and Development (R\&D) menurut Sugiyono (2009: 297) adalah metode penelitian yang digunakan untuk menemukan produk tertentu dan menguji keefektifan produk tersebut. Melalui, metode penelitian ini diperoleh informasi mengenai produk yang akan ditemukan untuk meningkatkan mutu dan kualitas pendidikan. Penelitian R\&D bertujuan mengembangkan dan menemukan produk penelitian yang valid melalui proses atau langkah yang bersifat siklus dan berulangulang, seperti pengujian lapangan, revisi produk, hingga lahirnya produk yang sesuai dengan tujuan yang ditetapkan.

\section{Langkah-langkah penelitian dan pengembangan (Sugiyono, 2009: 298), yaitu:}

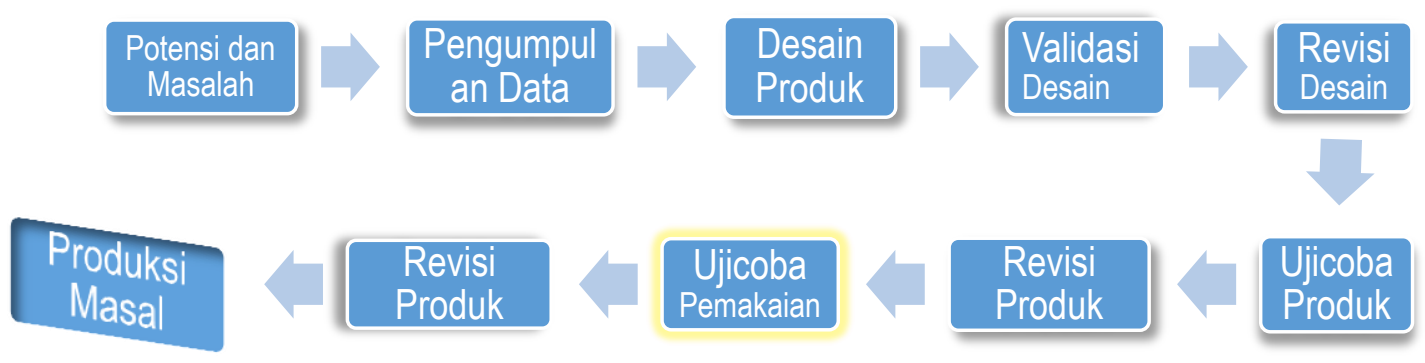




\section{a. Catatan Lapangan}

Tabel 1.1 Pengamatan Observer Terhadap Uji Produk

\begin{tabular}{|l|l|l|}
\hline \multicolumn{1}{|c|}{ Kegiatan Awal } & \multicolumn{1}{|c|}{ Kegiatan Inti } & \multicolumn{1}{|c|}{ Kegiatan Akhir } \\
\hline $\begin{array}{l}\text { Posisi tempat duduk siswa yang } \\
\text { kurang pas untuk pelaksanaan } \\
\text { diskusi dalam kelompok kecil } \\
\text { (ruang kelas dibentuk U) }\end{array}$ & $\begin{array}{l}\text { Guru terlalu dominan } \\
\text { dalam pemelajaran }\end{array}$ & $\begin{array}{l}\text { Kesimpulan diambil } \\
\text { alih oleh guru }\end{array}$ \\
\hline
\end{tabular}

Berdasarkan temuan pengamatan dalam pemelajaran oleh observer (Bu EF) tersebut diperoleh gambaran bahwa pemelajaran yang dilakukan belum terfokus pada siswa, sehingga pemelajaran tersebut belum menyenangkan bagi siswa. Pemelajaran tersebut masih didominasi oleh guru. Data tersebut dilengkapi dengan kondisi pembelajaran yang ada di kelas saat penelitian dilakukan, sehingga peneliti memutuskan menggunakan catatan lapangan agar data rinci dapat menggambarkan kondisi yang dimaksudkan. Data yang berasal dari catatan lapangan dapat dibaca secara rinci pada tabel berikut.

Tabel 1.2 Catatan Lapangan Peneliti Tentang Uji Produk

\begin{tabular}{|c|c|c|}
\hline Kegiatan Awal & Kegiatan Inti & Kegiatan Akhir \\
\hline $\begin{array}{l}\text { Penerangan materi cerita rakyat } \\
\text { tidak dapat menggunakan } \\
\text { powerpoint, sekilas diterangkan } \\
\text { dengan lisan (hanya } \\
\text { memberiitahu jenis-jenis cerita } \\
\text { rakyat dengan menekankan inti } \\
\text { dan contohnya seperti apa) dan } \\
\text { diperjelas di papan tulis. } \\
\text { (infokus sekolah hanya ada } 2 \\
\text { dari } 21 \text { kelas yang ada). }\end{array}$ & \begin{tabular}{lr}
\multicolumn{2}{l}{ Ketidakjelasan waktu } \\
dalam pemelajaran, \\
sehingga pelaksanaan \\
diskusi r panjang \\
akhirnya keSimpulan \\
memakai beberapa \\
menit jam istirahat \\
siswa.
\end{tabular} & $\begin{array}{l}\text { Karena waktu habis } \\
\text { dan diskusi masih } \\
\text { berjalan, akhirnya guru } \\
\text { menyimpulkan materi } \\
\text { yang telah dipelajari. }\end{array}$ \\
\hline $\begin{array}{l}\text { Posisi tempat duduk dan } \\
\text { pembagian kelompok dalam } \\
\text { satu kelompok yang kurang } \\
\text { bijaksana, hanya karena ingin } \\
\text { memantau siswa yang tidak aktif } \\
\text { ngapain. Posisi tempat belajar } \\
\text { dibuat berbentuk U, dengan } \\
\text { satu baris satu kelompok yang } \\
\text { terdapat } 9 \text { atau } 10 \text { orang) }\end{array}$ & $\begin{array}{lr}\text { Posisi tempat duduk } \\
\text { yang berbentuk U } \\
\text { membantu guru } \\
\text { melihat siswa yang } \\
\text { tidak aktif dan } \\
\text { menimbulkan antusias } \\
\text { siswa untuk } \\
\text { memberiikan } \\
\text { tanggapannya dalam } \\
\text { diskusi }\end{array}$ & $\begin{array}{l}\text { Penyimpulan yang } \\
\text { dibuat oleh guru hanya } \\
\text { berisi gambaran } \\
\text { umum tentang cerita } \\
\text { rakyat, bukan yang } \\
\text { diperdebatkan siswa. }\end{array}$ \\
\hline $\begin{array}{l}\text { - Siswa menentukan sendiri } \\
\text { anggota kelompoknya. }\end{array}$ & $\begin{array}{lr}\text { Diskusi } & \text { yang } \\
\text { diTemuankan } & \text { dalam }\end{array}$ & - \\
\hline
\end{tabular}




\begin{tabular}{|c|c|c|}
\hline Kegiatan Awal & Kegiatan Inti & Kegiatan Akhir \\
\hline $\begin{array}{l}\text { - Teks cerita rakyat yang } \\
\text { dibagikan terdapat } 3 \text { judul } \\
\text { yang berbeda di tiap } \\
\text { kelompok dan } 1 \text { judul yang } \\
\text { sama dalam satu kelompok. }\end{array}$ & $\begin{array}{l}\text { pemelajaran ini seru, } \\
\text { saat siswa-siswa } \\
\text { memperdebatkan } \\
\text { definisi, dan ciri khas } \\
\text { cerita, dan unsur- } \\
\text { unsur yang terkandung } \\
\text { dalam rakyat dari } \\
\text { contoh cerita rakyat } \\
\text { yang ada, baik dalam } \\
\text { kelompok kecil dan } \\
\text { kelompok besar dari } \\
\text { judul yang berbeda di } \\
\text { tiap kelompok dan } \\
\text { judul yang sama dalam } \\
\text { satu kelompok. }\end{array}$ & \\
\hline $\begin{array}{l}\text { Pemberian tugas oleh guru } \\
\text { diterangkan dengan bahasa } \\
\text { yang ringkas dan jelas }\end{array}$ & \begin{tabular}{lr} 
Siswa & boleh \\
menggunakan & $\mathrm{HP}$ \\
untuk & mencari \\
informasi & mengenai \\
\multicolumn{2}{l}{ cerita rakyat. }
\end{tabular} & \\
\hline
\end{tabular}

Berdasar catatan lapangan tersebut pada tabel 1.2 tersebut diperoleh gambaran bahwa uji model pemelajaran cerita rakyat melalui copywriting efektif (gairah dan antusias untuk aktif dan terlibat dalam diskusi kelas lebih banyak dan tidak hanya terjadi pada siswa yang bisaa aktif) tapi belum pemelajaran yang lebih baik, kekurangan-kekurangan dalam pemelajaran masih terdapat. Kekurangan tersebut dipengaruhi oleh faktor persiapan yang kurang, seperti persiapkan diri, dan Sarana-praSarana. Salah satu gambaran kesiapan diri guru dan Sarana penunjangnya dapat dibaca pada uraian berikut.
(1) Penilaian Silabus, RPP, dan Media Pemelajaran dari teman sejawat

Penilaian silabus, RPP, dan media pemelajaran ini merupakan penentu kelayakan dan kesesuaian kefektifan dan ketidakefektifan penerapan pengembangan model pemelajaran cerita rakyat melalui copywriting ini. Pada penilaian silabus dan RPP dilakukan oleh 2 orang observer yang merupakan teman sejawat. Sedangkan, penilaian media dilakukan oleh 3 orang observer yang juga merupakan teman sejawat yang mengajar di SMA Plus Negeri 3 Kota Bengkulu. Data dalam kegiatan ini secara rinci dapat dibaca pada tabel 1.3. berikut. 
Tabel 1.3 Data Observer Tentang Penilaian Silabus, RPP, dan Media Pelajaran

\begin{tabular}{|l|l|l|l|l|l|}
\hline \multirow{2}{*}{ No. } & \multirow{2}{*}{$\begin{array}{c}\text { Aspek } \\
\text { Penilaian }\end{array}$} & \multicolumn{5}{|c|}{ Kriteria Penilaian } \\
\cline { 3 - 6 } & \multicolumn{1}{|c|}{$\mathbf{1}$} & \multicolumn{2}{|c|}{$\mathbf{2}$} & $\mathbf{3}$ & \multicolumn{1}{|c|}{$\mathbf{3}$} \\
\hline 1. & Silabus & - & - & 2 org observer & - \\
\hline 2. & RPP & - & - & 2 org observer & - \\
\hline 3. & Media & - & - & 2 org observer & 1 org observer \\
\hline \multicolumn{2}{l}{ Total } & - & - & 6 & 1 \\
\hline
\end{tabular}

Penilaian silabus, RPP, dan media pemelajaran yang diperoleh dalam penerapan pengembangan model pemelajaran ini adalah penilaian 3 yang bermakna baik sekali, dan kondisi ini diraih oleh 6 . Sementara itu penilaian 4 (yang bermakna baik sekali), sebanyak 1 orang. Jadi, disimpulkan bahwa penerapan pengembangan model pemelajaran yang dilakukan di kelas XI IPS 3 SMA Plus Negeri 7 Kota Bengkulu sudah efektif. Keefektifan kegiatan pembelajaran ini secara rinci dapat dibaca pada uraian berikut.

\section{(2) Temuan Portofolio Copywrting Cerita rakyat}

Penilaian copywriting dalam penelitian ini adalah portofolio copywriting cerita rakyat siswa dalam kelompok (penilaian produk) yang menggunakan penskoran holistik skala 4. Penskoran holistik ini bertujuan untuk melihat karya tulisan sebagai produk keseluruhan, bukan sebagai bagian kelompok yang terpisah, disatukan, lalu menjadi keseluruhan. Sistem ini berasumsi bahwa semua faktor dalam menulis sama pentingnya (Agus Trianto, 2007: 28). Data portofolio copywriting cerita rakyat secara rinci dapat dibaca pada data berikut.

Tabel 1.4 Data Temuan Copywriting Siswa dalam Kelompok

\begin{tabular}{|l|l|l|l|l|l|l|}
\hline \multirow{2}{*}{ No. } & \multicolumn{1}{|c|}{ Nama Kelompok Siswa } & \multicolumn{5}{c|}{ Kriteria Penilaian } \\
\cline { 3 - 7 } & & $\mathbf{1}$ & $\mathbf{2}$ & $\mathbf{3}$ & $\mathbf{4}$ \\
\hline 1. & Kel. M. NG & - & - & 1 & - \\
\hline 2. & Kel. DR & - & - & - & 1 \\
\hline 3. & Kel. DE & - & - & 1 & - \\
\hline Total & & $\mathbf{0}$ & $\mathbf{0}$ & $\mathbf{2}$ & $\mathbf{1}$ \\
\hline
\end{tabular}

Maka, data copywriting siswa tersebut diperoleh penilaian 3. yang berarti karangan cukup baik organsasi, isi, penggunaan bahasa, dan penguasaan mekanik. Namun, kurang imajiasi dan kreativitas. Dengan kata lain, Temuan copywriting dari pengembangan model pemelajaran cerita rakyat melalui copywriting yang diterapkan di kelas XI IPS 3 sudah efektif. Effektivitas temuan penelitian tersebut dilengkapi dengan data yang berasal dari respon sisiwa. Data yang dimaksudkan dapat dibaca pada uaraian berikut. 
(3) Respon Siswa tehadap Pemelajaran Cerita Rakyat Melalui Copywriting

Respon yang diperoleh peneliti dari uji model pemelajaran melalui copywriting tersebut adalah senang. Respon "senang" yang didapat dari siswa berjumlah 26 orang dari 28 orang siswa yang ada. Maka, keSimpulannya bahwa penerapan model pemelajaran di kelas XI IPS 3 pada hari Rabu, 16 Mei 2012 di SMA Plus Negeri 7 Kota Bengkulu ini efektif dan dapat dipergunakan lagi untuk model pemelajaran cerita rakyat selanjutnya, tapi sebaiknya sebelum digunakan diperbaiki terlebih dulu. Temuan ini dilengkapi dengan Temuan uji produk berikut.

\section{(4) Temuan Pengujian Produk}

Maka, Temuan ujicoba
produk
pengembangan
pemelajaran cerita rakyat melalui copywriting) yang dilakukan di kelas XI IPS 3 SMA Plus Negeri 7 Kota Bengkulu adalah efektif, menarik, dan sesuai.

(5) Pembahasan Produk

Berdasarkan Temuan ujicoba produk yang dilakukan bahwa pengembangan model pemelajaran cerita rakyat melalui copywriting ini efektif, menarik, dan sesuai. Walau, produk masih memerlukan revisi atau perbaikan yang banyak.

\section{Simpulan dan Saran}

Pengembangan model pemelajaran cerita rakyat ini diperoleh keSimpulan, yaitu: pengembangan model pemelajaran cerita rakyat melalui copywriting yang diterapkan di kelas XI IPS 3 SMA Plus Negeri 7 Kota Bengkulu adalah efektif, menarik, dan sesuai. Walau, produk masih memerlukan revisi atau perbaikan yang banyak.Produk ini dikatakan sesuai karena produk yang disuguhkan sesuai dengan SK dan KD yang ada, sesuai dengan indikator ketercapaian materi cerita rakyat dalam keterampilan membaca, dan sesuai dengan kebutuhan siswa dalam pencapaian kompetensi. Dan, produk ini menarik karena produk ini di dalamnya terdapat segi ekonomis dan praktis. Artinya, metode-metode pemelajaran yang diterapkan adalah metode-metode yang sering dipergunakan guru dalam pemelajaran namun disuguhkan lebih interaktif dan berfokus pada siswa (membelajarkan siswa), dan media pemelajaran yang digunakan adalah cerita rakyat yang dipadukan dengan powerpoint sebagai alat perubahan zaman yang dapat memberikan pengalaman belajar.

\section{A. Saran Penggunaan}

Sebaiknya, peneliti yang akan merancang pengembangan dan penelitian bentuk pemelajaran harus lebih mempersiapkan diri (pengetahuan dan pemahaman tentang pengembangan, pemelajaran, dan copywriting), dana (akomodasi selama penelitian, baik transportasi, penggandaan media pemelajaran, dsb.), stamina (kondisi mental dan fisik yang harus selalu fit), dan waktu yang luar bisaa agar lebih terkonsep dan mendapatkan Temuan yang lebih baik dan memuaskan. Terus semangat dan pantang menyerah. 
Daftar Pustaka

Indriana, Dina. 2011. Mengenal Ragam Gaya Pemelajaran Efektif. Yogyakarta: Penerbit Diva Press.

Indriati, Etty. 2006. Menulis Karya IImiah Artikel, Skripsi, Tesis, dan Disertasi. Jakarta: PT Gramedia Pustaka Utama.

Joyce, Bruce, Marsha Weil, dan Emily Calhoun. 2009. Models of Teaching Model-Model Pengajaran.

Yogyakarta: Pustaka Pelajar.

Komalasari, Susi. 2010. Kelayakan Media Pemelajaran Terhadap Media Pemelajaran Powerpoint.Tesis Tidak Diterbitkan. Bengkulu: Program Pascasarjana Pendidikan Bahasa Indonesia, FKIP UNIB.

Kosasih, Engkos. 2006. Cerdas Berbahasa Indonesia Untuk SMA/MA Kelas $X$. Jakarta: Penerbit Erlangga.

Kosasih, Engkos. 2006. Cerdas Berbahasa Indonesia Untuk SMA/MA Kelas XI. Jakarta: Penerbit Erlangga.

Mafrukhi, dkk. 2007. Kompeten Berbahasa Indonesia untuk SMA Kelas XI. Jakarta: Erlangga.

Muslich, Masnur. 2010. Text Book Writing Dasar-Dasar Pemahaman, Penulisan, dan Pemakaian Buku Teks. Yogyakarta: AR-RUZZ MEDIA.

Pannen, Paulina dan Purwanto. 2001. Penulisan Bahan Ajar. Jakarta: Proyek Pengembangan Universitas Terbuka Direktorat Jenderal Pendidikan Tinggi Departemen Pendidikan Nasional.

Pengurus Jurnal Pascasarjana (S2) Pendidikan Bahasa Indonesia. 2010. Jurnal Ilmiah: Bisa, Edisi 2 Juli 2010. Bengkulu: Program
Pascasarjana (S2) Pendidikan Bahasa Indonesia.

Prahana, Naim Emel.1997. Cerita Rakyat dari Bengkulu 2. Jakarta: PT Grasindo.

Prastowo, Andi. 2011. Panduan Kreatif Membuat Bahan Ajar Inovatif Menciptakan Metode Pemelajaran yang Menarik dan Menyenangkan. Yogyakarta: DIVA Press.

Rusman. $2010 . \quad$ Model-model Pemelajaran Mengembangkan Profesionalisme Guru. Jakarta: Rajawali Pers.

Sanjaya, Wina. 2008. Kurikulum dan Pemelajaran Teori dan Praktik Pengembangan KTSP. Jakarta: Prenada Media Group.

Sayuti, Suminto A.. 1996. Apresiasi Prosa Fiksi. Jakarta: Departemen Pendidikan dan Kebudayaan Direktorat Jendral Pendidikan Dasar dan Menengah Bagian Proyek Penataran Guru SLTP Setara D3 Tahun 1996-1997.

Sharan, Shlomo. 2009. Handbook of Cooperative Learning -Inovasi Pengajaran dan Pemelajaran untuk Memacu KeberTemuanan Siswa di Kelas. Yogyakarta: Imperium.

Slaunwhite, Steve. 2006. Memulai dan Menjalankan Bisnis Copywriting. Jakarta: Abdi Tandur.

Sugiyono. 2009. Metode Penelitian Kuantitatif Kualitatif dan $R \& D$. Bandung: Penerbit Alfabeta. 